ENTREVISTA A DANIEL JADUE JADUE:

\title{
"CUANDO UNO MIRA EL PROGRAMA DE LA UP, PUEDE TENER LA TRISTE TENTACIÓN DE REÍRSE Y DECIR: 'CINCUENTA AÑOS Y NO HA PASADO NADA, SEGUIMOS TENIENDO LOS MISMOS PROBLEMAS DE 1970"”
}

Jennifer Abate Cruces 


\title{
DANIEL JADUE JADUE:
}

\author{
"Cuando uno mira el programa de la UP, \\ puede tener la triste tentación de reírse $y$ \\ decir: 'cincuenta años y no ha pasado nada, \\ seguimos teniendo los mismos problemas \\ de 1970"'
}

El alcalde de Recoleta, militante del Partido Comunista y uno de los favoritos de las encuestas en la carrera presidencial, evalua en esta entrevista los triunfos $y$ aciertos del gobierno de la Unidad Popular, recuerda con emoción "la profunda convicción democrática" del presidente Salvador Allende y se muestra convencido de las posibilidades que ofrece una rearticulación de las izquierdas en la que su partido se ha llevado todas las miradas.

Por Jennifer Abate Cruces 
Arquitecto y sociólogo de la Universidad de Chile, Daniel Jadue, 53 años, alcalde de Recoleta y, para muchos, la más segura carta de la izquierda para la próxima elección presidencial, se siente a sus anchas hablando sobre una historia que conoce y admira: la del ascenso del presidente Salvador Allende y los mil días de la Unidad Popular. En esta conversación, que mezcla pasado y presente (y mucho futuro), el político evalúa el proyecto del gobierno popular y extrae lecciones que, a su juicio y pasadas por el tamiz de la historia, nos servirían para abordar los procesos de cambio y construcción actuales.

-A diferencia del 11 de septiembre, que siempre es una fecha trágica en nuestro país, los 4 de septiembre evocan aspectos que tienen que ver con el triunfo de la Unidad Popular. Este año se conmemoraron cincuenta años del triunfo de la UP en medio de la campaña por el plebiscito. ¿De qué manera recordó usted este medio siglo? ¿Cuáles fueron los balances que hizo a cincuenta años de la UP?

-Yo siempre lo recuerdo con mucha emoción porque es un proceso que me llega muy de cerca por mi formación política, también masónica, y quizás este año en particular traje a colación otros cálculos. ¿A qué me refiero? Entre la aprobación de la nueva Constitución y el triunfo de la Unidad Popular pasaron cincuenta años, y entre el golpe de Estado y el 18 de octubre pasaron 46. Ambas fechas marcan dos inicios de incorporación más plena o de reconstrucción, en el caso del golpe de Estado, del poder deliberante de los sectores populares. Son cincuenta años donde la derecha, cada vez que tuvo necesidad, recurrió a las violaciones de derechos humanos, a las masacres, a las matanzas de trabajadores y trabajadoras indefensas precisamente para resistirse a la pérdida de sus privilegios. En particular, este 4 de septiembre respondía a un contexto distinto a los demás, rodeado de más esperanza, donde efectivamente parecía que el proceso de acumulación de fuerzas estaba llegando a su fin y que por primera vez en muchos años de espera el pueblo volvía a creer que era capaz de subirse al escenario de la historia, de ser protagonista principal. Esa quizá fue la reflexión más potente de este 4 de septiembre.

- ¿Se siente interpelado, como figura política central del Chile actual, por este reencantamiento del pueblo con la política? Los procesos populares luego son conducidos por las y los políticos.

- Lo primero es que yo no comparto un juicio implícito que existe en su pregunta. No comparto que este proceso sea conducido por los políticos. Yo asumo que la 
conducción del proceso está alojada en la ciudadanía. Los que pretenden o los que esperan o los que sueñan que están conduciendo el proceso político son los que van a llevar al pueblo a lograr su objetivo, pero esa falsa pretensión demuestra que todavía siguen sin entender nada de lo que está pasando, porque la burbuja que habitan, el lugar y ese espacio de confort donde han habitado los últimos treinta años les impide entender. Ellos tienen esta pretensión de conducir el proceso, que es finalmente el derrotero que le plantearon al pueblo el 15 de noviembre. Ahí hay un intento del sistema político, de una parte mayoritaria del sistema político, por tomar el control, por decirle al pueblo: "mira, de esta crisis salimos, pero no salimos por ustedes, salimos nosotros", y yo no siento que hoy haya disposición en el pueblo a aceptar de forma pacífica y resignada esta pretensión. Por lo tanto, aquí hay que tener mucho cuidado, porque el proceso de nueva Constitución puede terminar muy bien, pero también puede terminar muy mal. Cualquiera que se quede trabado en la calculadora de quién saca el tercio, quién tiene derecho a veto, quién logra impedir la mayor cantidad de cambios — que es lo que está haciendo la derecha mientras el centro trata de cooptar una Constitución "absolutamente neutra", que ni siquiera aspira a recuperar en algo el tiempo perdido-, va a terminar enfrentado a una realidad en la que finalmente el pueblo va a decidir si lo acepta o no lo acepta. Este proceso está lleno de "trampas", lleno de "obstáculos", no sé si llamarlos trampas u obstáculos, pero me refiero a los dos tercios, al plebiscito de entrada sin votación obligatoria, al plebiscito de salida con voto obligatorio, a que no se pueda hablar de algunas materias en la discusión. Es decir, el sistema político se ha puesto a sí mismo como el soberano y le ha delegado a una convención constitucional electa por el pueblo una parte de las atribuciones que el soberano tiene, y yo no sé si ese es el sentir profundo del soberano; para mí el soberano sigue siendo el pueblo.

Este proceso puede terminar formidable, pero también puede ser un tremendo desastre, porque si este proceso no termina dando respuestas satisfactorias, podríamos terminar en algo que no nos gustara, es decir, si la ciudadanía movilizada llega a sentir solo el aroma de que fue engañada nuevamente, esto no pinta para nada bueno y vamos a tener que acostumbrarnos a ver un proceso sumamente dinámico, que va a estar sometido a un estrés permanente, con una ciudadanía que va a exigir permear el sistema cada vez que lo crea necesario. Ya lo vimos con los escaños reservados, es una verdadera vergüenza lo que se aprobó.

Me encantaría que los que firmaron el acuerdo se atrevieran a hacer un plebiscito en donde votáramos artículo por artículo el acuerdo, pero ellos le tienen medio a la ciudadanía. Por ejemplo, la gran crítica a Camila Vallejo por presentar un proyecto para cambiar los dos tercios. Ellos creen que son los únicos que pueden opinar, creen que son los únicos que pueden cambiar cosas que no están planteadas, se apoderaron de tal manera que esto les puede pasar una factura de dimensiones que no alcanzan siquiera a avizorar. 


\section{- La crisis social y la crisis sanitaria nos develaron condiciones de vida que} habíamos ocultado debajo de la alfombra. Esto ha conducido a muchas redefiniciones políticas, por ejemplo, sobre el tamaño y rol del Estado. En este contexto, ¿cree usted que sirve volver a mirar el proyecto de la Unidad Popular? ¿Qué podríamos extraer de ese proceso que pudiera ayudarnos en el escenario actual?

- Siempre sirve para aprender de los errores, para reconocer los aciertos y los avances que iban en la dirección correcta y que fueron suprimidos por el golpe de Estado. Sirve, sobre todo, para imaginarnos la actualización del proceso. Por ejemplo, hoy, cuando unos aspiran a redefinir el rol del Estado, hay algunos que pueden pensar que esto tiene que ver con volver a fortalecer al Estado central, mientras que yo soy más partidario de fortalecer a los gobiernos locales dentro del aparato del Estado y avanzar en la destrucción del Estado central como instrumento de dominación de clases, lo que no implica para nada destruir el Estado central, sino que despojarlo de poder, de atribución y de recursos en favor de lugares que están más cerca en la estructura institucional a la ciudadanía.

Cuando nosotros decimos: "mira, logramos resolver en Recoleta el tema de los medicamentos con la Farmacia Popular", algo que en veinticinco años no pudo resolver el Estado central; "logramos resolver los audífonos populares", algo en lo que el Estado se demora tres años y nosotros resolvemos en tres días; "logramos superar incluso la discusión acerca de la eliminación del IVA y el precio fijo para el libro con la Librería Popular"; "logramos resolver el tema del mercado completamente abusivo e inescrupuloso del arriendo en el tema de la vivienda con la Inmobiliaria Popular", hablamos de temas que el Estado central nunca quiso resolver, que ni siquiera se planteaba, porque pensaba que todo lo podía resolver el mercado. Creo que hay una tensión. Cuando uno mira para atrás y ve en la actualidad los procesos progresistas y de izquierda en América Latina, hay una deuda que tiene que ver con la redistribución de poderes, atribuciones y recursos entre los distintos niveles nacionales y subnacionales del Estado en términos de cómo potenciamos la región, en los gobiernos locales por sobre el Estado central, y eso requiere soltar: soltar recursos, soltar poder, soltar atribuciones y empezar a mirar esta redistribución de atribuciones, potestad y recursos desde los municipios hacia arriba, entendiendo que el prestador fundamental de todo servicio debería ser el municipio, y que lo que no puede prestar el municipio, por diversas razones, lo tiene que prestar el nivel superior, y lo que no puede prestar el gobierno regional, lo tiene que prestar el nivel superior, que es el nacional, pero nunca al revés. 


\section{—Respecto al presidente Salvador Allende, ¿qué es lo que usted rescata de su figura?}

- Su profunda convicción democrática, la profunda fraternidad con la cual llevaba su vida política, rescato los valores y principios de Allende, pero además rescato el programa. Cuando uno mira el programa, las cuarenta medidas, uno puede tener la triste tentación de reírse de manera un poco socarrona, un poco sarcástica, y decir: "cincuenta años y no ha pasado nada, seguimos teniendo los mismos problemas de 1970". Seguimos pensando en asegurar condiciones básicas mínimas, que no son las mismas del medio litro de leche, pero cómo combatimos hoy un problema tan grave como es la obesidad. El tema de la vivienda: ocho de las cuarenta medidas tenían que ver con el derecho a vivir dignamente. Uno mira y dice: "cuánto hemos retrocedido para que Chile hoy esté discutiendo sobre integración social". Algunos pretenden ser los adalides de la integración social cuando hace dos años destruyeron la villa San Luis; el mismo que permitió que la destruyeran quiere aparecer como el guaripola de la integración. Allende construyó vivienda social en medio de la ciudad consolidada para provocar la integración social. Uno mira lo que Allende hizo con los pueblos originarios: nunca, ningún gobierno como Allende ha devuelto tantas tierras, nunca hubo más consideración con la cosmovisión, la relación con los parlamentos, la relación con los lonkos. Uno mira los miles de millones de dólares que las trasnacionales se han llevado sin dejar un peso en Chile. Uno mira la educación, recuerde el proyecto de la Universidad Técnica, una maravilla, la Escuela de Artes y Oficios, y hoy, cincuenta años después, estamos viendo cómo formamos técnicos para la necesidad de las empresas. Es muy triste que un país se dé vuelta sobre sí mismo mientras que a partir de nuestras riquezas se han enriquecido otros y no nosotros.

Allende fue un hombre que se adelantó a su tiempo, que le tocó vivir lo que venía después, porque además, dentro de la capacidad futurológica que tienen los marxistas, Allende logró proyectar al futuro las tendencias del capitalismo, como lo hace Marx, y se imaginó un mundo donde iba a caer el empleo, donde el desempleo estructural aumentaría, donde la riqueza se seguiría concentrando y donde habría que avanzar en proteger la vida de las y los trabajadores mas allá del trabajo mismo, una discusión muy actual.

\section{-A la hora de los balances, ¿cree usted que hubo procesos políticos al interior del gobierno de la Unidad Popular que pudieron ser mejor conducidos?}

— Sin duda. O sea, la responsabilidad del PC, la irresponsabilidad del MIR.... Hay un libro de Julio Pinto, Cuando bicimos historia. La experiencia de la Unidad Popular, 
donde él analiza este antinomio entre reforma y revolución y llega a plantear que algunas veces la izquierda se ciega a sí misma y no entiende que, en algunos minutos, lo más revolucionario es ser reformista y que, en otros, lo más reformista es ser revolucionario. Es una definición que cuando la leí, hace muchos, muchos años atrás, me quedó absolutamente impregnada y que hasta el día de hoy mantengo. Además, da mucha lata, porque todos los que en esa época eran partidarios de la violencia política como método para acceder al poder, después, para la recuperación democrática, se pusieron de acuerdo y dejaron fuera al único que no era partidario de la vía armada para acceder al poder. Ninguna autocrítica y le pasan la boleta al partido más institucional y democrático de Chile, que es el Partido Comunista, y entran al escenario de la postdictadura caminando como si fueran los grandes héroes de Chile, los que recuperaron la democracia sin siquiera decir "agua va", nos equivocamos, pedimos disculpas. Creo que hay una administración absolutamente ineficaz e ineficiente de las diferencias entre las izquierdas que nos persigue hasta hoy, pensando, además, que una parte de esa izquierda, que era la más revolucionaria, hoy es la más neoliberal.

-Precisamente a ese tema quiero llevarlo, al futuro de las izquierdas en el contexto actual. Estamos viendo una rearticulación de ese sector. En las últimas semanas causó revuelo la decisión de Revolución Democrática, uno de los partidos más visibles del Frente Amplio, de tender puentes con el Partido Comunista, lo cual fue enormemente criticado por la derecha y por la ex Concertación, a pesar de que esta hizo una alianza con el PC que dio vida a la Nueva Mayoría. ¿Ve usted posible una articulación de las izquierdas tal como la que llevó al triunfo a Salvador Allende?

-Sí, claro. De las izquierdas, no del centro [risas]. Aquellos de la Concertación que criticaron que esta decisión del Frente Amplio fue un tremendo error, primero dejan de manifiesto que les molesta que otros puedan ganar con el Partido Comunista y no ellos, o sea, a ellos les gusta el PC cuando les permite ganar, pero cuando el PC les permite ganar a otros, no, eso no lo consideran posible y muestran su doble estándar. El segundo error es que parece que tuvieran poca memoria, incluso los que se van del Frente Amplio, porque este nace con un proyecto para ir precisamente contra el modelo, antineoliberal y contra el duopolio que había gobernado Chile durante treinta años. La decisión que acaba de tomar el Frente Amplio le hace honor a su propia historia, nacimiento y origen. Si a alguien le llama la atención es porque está mal informado. Quienes se fueron tienen todo el derecho de cambiar si fueron seducidos por el modelo y se quieren juntar con aquellos que creen que no hay que cambiar el neoliberalismo, sino que solo corregirlo; es un cambio de ellos 
y es legítimo, se pueden ir a la socialdemocracia neoliberal. Ellos tendrán que dar explicaciones si fue porque cambiaron de forma de pensar o porque se sienten más cerca del poder allá que acá. Creo que hay dos acciones racionales, pero respecto de fines distintos, como diría Max Weber en Economía y sociedad: hay una parte del Frente Amplio que toma una decisión y ejerce una acción racional respecto de principios y valores, y hay otros que toman una decisión racional respecto a fines, ambos legítimos en la política, es una opción de cada cual.

Creo que lo que está pasando es la rearticulación de las izquierdas, con Chile Digno, con el Frente Amplio. Quienes están saliendo del Frente Amplio son los que eran parte de esa hiperamplitud que el FA expresaba en un comienzo, en esa amplitud estaban hasta exfuncionarios del primer gobierno de Piñera, o sea, era un frente bien amplio. Ahora sigue siendo bien amplio, pero no tan amplio, porque cuando uno es muy amplio se termina desdibujando, que es lo que la izquierda no quiere que le pase cuando algunos llaman de manera vacía a la unidad, en términos binarios. Algunos no queremos confundirnos. Imagínese lo difícil que es para los comunistas pactar con un partido que hasta el día de hoy no le explica a Chile por qué se puso a disposición de un gobierno extranjero para derrocar a su propio gobierno en el setenta, todavía no le dan una explicación a Chile de por qué traicionaron el programa de gobierno de la doctora Bachelet en su segundo gobierno, todavía no dan una explicación a Chile de por qué el presidente — no estoy hablando de los militantes de base, estoy hablando del presidente- de la Democracia Cristiana afirmó que no se había leído el programa [de la presidenta Michelle Bachelet]. Ellos apuestan a la tesis de la diferenciación: cuando son gobierno se comportan como si fueran de oposición y cuando son de oposición se comportan como si fueran de gobierno, apelando a esta capacidad ilimitada que dicen tener de conversar con la diferencia, menos con el PC. Pueden conversar con todos, hasta con los que fueron parte de la dictadura, pero no con el Partido Comunista, que nunca ha estado en una dictadura, que nunca ha hecho ninguna matanza de trabajadores, que nunca ha gobernado este país solo, que nunca se ha puesto a disposición de otro gobierno para derrocar al propio; pueden conversar con todos ellos, menos con nosotros, pueden conversar incluso con estafadores de bancos, pero no con los comunistas. Eso los muestra de cuerpo entero.

-Una de las características de las movilizaciones tras la revuelta del 18 de octubre fue la ausencia de banderas de partidos políticos, que han sido enormemente cuestionados. ¿Se ha sentido interpelado el Partido Comunista por este movimiento social?

- Mire, la primera vez que yo fui a la Plaza de la Dignidad, para las manifestaciones del 18 de octubre, alguien me dijo: "alcalde, qué bueno verlo aquî". Yo le dije: "no, 
qué bueno verlo a usted aquî", porque yo vengo a protestar a este mismo lugar desde el 86, el 89, el 94, el 97, el 2001, el 2006, el 2011 y el 2016. Encuentro formidable que todos vengan llegando, pero al Partido Comunista esto no lo interpela. Hay mucha gente que todavía no se entera de cuál era la posición histórica del PC, o sea, nosotros éramos contrarios a las AFP antes de los que crearon No+AFP; nosotros éramos contrarios a la Constitución de Pinochet antes de los que hoy protestan por cambiar la Constitución nacieran. La campaña, la caricatura hace que todos se confundan en una misma cosa. El Partido Comunista nunca ha tratado de hegemonizar y mucho menos utilizar al movimiento social, participa como parte del movimiento; no necesitamos llevar nuestras banderas, hemos estado ahí siempre. Desde el noventa a la fecha, cuántas veces el PC o la Jota [Juventudes Comunistas] han dirigido las federaciones estudiantiles, las de los secundarios, la ANEF [Agrupación Nacional de Empleados Fiscales], la CUT [Central Unitaria de Trabajadores], todos los movimientos sociales, el movimiento de la salud. ¿Qué otro partido puede mostrar la misma representación en todos estos movimientos populares, que son los mismos que han venido año tras año convocando a las mismas manifestaciones en una línea incremental sostenida? De hecho, yo no le llamo estallido social, sino revolución de octubre o el octubre chileno, como usted quiera llamarle. ¿Por qué? Porque es un proceso largo de acumulación de fuerza. Los que le llaman estallido social, lo que quieren dar a entender es que no tiene conducción, que es espontáneo, que no hay con quién conversar. Se cansaron de protestar todos por separado por sus intereses particulares y se unieron para protestar todos contra el modelo, ese es un proceso que está descrito en numerosos textos y que es lo que esta dándose en Chile. Todo lo otro para mí es música.

¿En qué nos interpela? En que quizás no nos camiseteamos tanto durante todo este tiempo y al no camisetearnos, mucha gente no se enteró de que estuvimos siempre ahí, quizás esa es una interpelación, pero ¿cuál otra? ¿O nadie se acuerda de Rodrigo Rocco, Marisol Prado, Iván Mlinarz y todos los compañeros que les siguieron? ¿De Bárbara Figueroa, Pepe Figueroa, su padre, el mismo Lautaro? Uno mira la historia y ve a los mismos personajes durante treinta años convocando, con el objetivo de masificar, llegar a las bases y masificar el descontento. Nadie puede decir que el PC dirigió esto, no, eso es absurdo, pero ¿alguien puede decir que nosotros no estuvimos ahí y que no era nuestro objetivo lo que pasó? No, tampoco, porque lo veníamos anticipando. De hecho, ese libro que lanzamos hace pocos días, No lo vieron venir, que recopila una serie de columnas desde 2005 a la fecha, sirve para decirles: "no, hubo algunos que lo estábamos anticipando desde hace veinte años, treinta años, los que no lo vieron venir fueron ustedes, que se acercaron tanto al espacio del poder que terminaron fundiéndose con él”. Imagínese una telaraña, una mosca que vuela cerca de la telaraña y es atraída por su majestuosidad, su geometría perfecta, su belleza, su liviandad, su hermosura, y se acerca a ver la telaraña hasta 
que la roza, sencillamente, y ahí quedó pegada hasta ser sucumbida por esa telaraña que tanto le atrajo. Eso le pasó al sistema político chileno: se acercaron tanto a la telaraña del poder que mientras más trataban de moverse, más los agarraba para abajo, más se agarraban a él, más se inmovilizaban.

-Usted y otras figuras de su partido denuncian constantemente el anticomunismo no solo en la política, sino que también en la sociedad chilena. Sabemos que esto tiene raíces históricas en que el PC fue declarado ilegal y sus militantes, perseguidos y perseguidas, y que se profundiza con la dictadura cívico-militar de Augusto Pinochet. ¿Por qué, a su juicio, esto se perpetúa incluso después de la conquista de la democracia y se mantiene hasta el día de hoy?

- Porque creo que somos uno de los pocos actores políticos que efectivamente ponemos en riesgo los privilegios de los que más tienen, de los abusadores de siempre, los otros no. Yo, una vez, después de sumar la cantidad de juicios que me había puesto la derecha en mi primer periodo como alcalde, conversé con un colega con el cual tengo alguna relación, no lo voy a nombrar, pero ya lleva más de 28 años como alcalde. Le pregunté cuántas veces lo habían demandado. "Ninguna", me respondió. “'Tú no asustas a nadie!”, le dije. La revolución avanza generando una contrarrevolución cada vez más fuerte, radical y cruel. La crueldad es ese sentimiento que pretende aniquilar al adversario. Yo leí la Fratelli tutti, la encíclica del Papa, y hay un minuto en que dice: "eliminar al adversario se ha convertido en el fin de la política". Eso es así: cuando empiezan a ver resquebrajadas las bases que sustentan sus privilegios, se radicalizan y te convierten en chivo expiatorio de todos los males. Nunca hemos gobernado, nunca hemos tratado de desarrollar nuestro programa, nunca hemos masacrado a nadie, nunca hemos sido parte de ninguna dictadura, nunca nos hemos puesto a disposición de un gobierno extranjero, pero los males de Chile son culpa de los comunistas, mire qué notable, o sea, es una caricatura tan burda que hoy ni siquiera se sostiene y la gente empieza a darse cuenta. ¿Cuándo? Cuando desde los gobiernos locales de los comunistas empezamos a mejorar problemas y a solucionar aquellos que nadie había podido solucionar y empezamos a demostrar que sí se puede y a cambiar con una rapidez bastante inusitada el imaginario colectivo. Mis colegas me lo decían: "oye, cada vez que haces una iniciativa en Recoleta, después en mi comuna me preguntan: y nosotros, ¿cuándo?”.

-E1 gobierno de la UP tenía un programa claro contenido en las cuarenta medidas. En la perspectiva de la rearticulación de las izquierdas de la que ya hablamos, ¿cree posible enfrentar el proceso constitucional con un programa claro y un horizonte definido desde ese sector? 
- Hay tanto avance en aquello que pocos se lo imaginarían. Respecto al desafío de hacerlo correr paralelamente a la discusión constitucional, ahí hay un espacio difuso de intersección donde vamos a tener que jugar con mayor audacia, pero con una mayor capacidad de interlocución con la ciudadanía. Hay mucho avance en el programa. Yo creo que todos los que dicen que el programa es el problema le mienten a Chile, porque aquí el único programa que hay que hacer y llevar adelante - en un trayecto y no en un proyecto; hay una diferencia fundamental entre un proyecto, que hace alusión a un modelo ideal, y un trayecto, que define una dirección en la cual moverse- es el que plantea el movimiento. Mientras nos movamos en esa dirección, más allá de lo que logremos avanzar, mientras claramente nos movamos en esa dirección y no en otra, el programa está hecho, yo creo que hay mucha claridad sobre eso. Hay medidas puntuales, hay programas más complejos, como una reforma tributaria verdaderamente progresiva, una reforma laboral, establecer el derecho a huelga en nuestro país, pero en serio, que el derecho a propiedad no sea absoluto, sobre los recursos naturales, sobre la sustentabilidad, sobre transformar el agua en un bien nacional de uso público.

\section{—Sobre la paridad también, espero.}

- Por supuesto. La paridad ha ido avanzando y no tiene que estar solo en el Congreso, sino también en el Consejo de Defensa del Estado, en la Corte de Apelaciones, en la Corte Suprema, en todas las instancias de poder, en los gobiernos comunales, en los gobiernos regionales, en los directorios de las empresas. Yo voy bastante más allá: remuneración del trabajo doméstico, reconocimiento constitucional y remuneración con cargo al presupuesto de la nación del trabajo doméstico. Nosotros, los comunistas y las comunistas, creemos que la contradicción principal es capital versus trabajo, y para empezar a resolver esa contradicción no puede haber ningún trabajo en la sociedad que, después de hecho, no se remunere, porque ahí está la generación de la riqueza, en la extracción del valor del trabajo y en su ubicación en un lugar distinto de donde ese trabajo se realiza. ¿Quién te puede explicar que el trabajo fuera de tu casa vale 400 lucas y el de tu casa vale cero? ¿Dónde está el tema de igual pega, igual paga? A mí me ha sorprendido mucho que esta no haya sido la primera demanda del movimiento feminista, yo la vengo planteando hace seis años, hoy ya la hemos metido en numerosas discusiones, es parte del programa. Incluso antes de la renta básica universal que plantean algunos debe haber un reconocimiento del trabajo doméstico y del trabajo de cuidados. Imagínese cómo resolveríamos los problemas de violencia intrafamiliar, no totalmente, pero ¿se imagina que ninguna mujer tuviera que aguantar a un maltratador por depender de él socioeconómicamente? 
Son temas centrales, junto con la buena educación, la salud universal, el sistema de pensiones. Todo lo que he dicho está en las demandas de la ciudadanía. Hay algunas cosas que no las ha planteado la ciudadanía, pero que las venimos planteando nosotros hace mucho. Un Ministerio del Mar, hay que fusionar una cantidad de ministerios, pero crear otros que son fundamentales: el desarrollo de la labor marítima en nuestro país, de la pesca, no puede estar supeditado al Ministerio de Agricultura. Aquí no hay dos opciones: o sintonizas con el soberano o no sintonizas; para el que sintoniza, el programa está clarísimo.

\section{Para finalizar, ¿qué le responde al Premio Nacional de Humanidades y Ciencias Sociales y hoy candidato a la convención constitucional, Agustín Squella, que planteó que no votaría por usted porque "el PC no es amigo de las libertades individuales"?}

—Lo primero es que discutamos sobre libertades individuales, discutamos si los que esperan darle su voto son partidarios del aborto libre e informado hasta las doce semanas o si son partidarios del matrimonio igualitario o si son partidarios o eran partidarios hace quince años del divorcio, de la igualdad de los hijos nacidos fuera del matrimonio. Yo soy partidario de la legalización de las drogas. Preguntémosle al señor Squella si él es partidario de aquello para que veamos quién es más amigo de las libertades. Ahora el señor Squella se ha desnudado de cuerpo entero, primero porque algunos le recordaron que celebraba con un asado todos los 11 de septiembre, y segundo, porque efectivamente la única libertad que abraza es la de tener el poder del dinero. Hablemos de libertades, yo estoy dispuesto a debatir. Ahora, usted comprenderá que debatir con alguien que celebraba los 11 de septiembre no me resulta muy atractivo.

-É1 ha dicho que no celebraba el golpe de Estado, sino que se reunía con amigos y que el dueño de casa era partidario de izar la bandera chilena el 11 de septiembre.

-Yo, la verdad, no voy a fiestas de cumpleaños si no estoy de acuerdo con el cumpleaños. Bueno, él podrá decir lo que quiera, pero efectivamente creo que no vale la pena contestarle a las caricaturas que hacen de nosotros porque hay libertades con las cuales en su mundo nunca han comulgado y que son mucho más relevantes desde mi perspectiva. Seguramente él está de acuerdo con que las mujeres sigan siendo obligadas a parir cuando no quieren hacerlo. Yo estoy dispuesto a discutir y le puedo asegurar que soy bastante más liberal que Squella y que todos aquellos que han recibido esos votos en los últimos treinta años. 